\title{
Sodium hydrogen sulfate as effective and reusable heterogeneous catalyst for the one-pot preparation of amidoalkyl naphthols
}

\author{
Hamid Reza Shaterian* and Hossein Yarahmadi \\ Department of Chemistry, Faculty of Sciences, University of Sistan and Baluchestan \\ PO Box 98135-674, Zahedan, Iran \\ E-mail: hrshaterian@hamoon.usb.ac.ir
}

\begin{abstract}
An efficient synthesis of amidoalkyl naphthols using sodium hydrogen sulfate as heterogeneous catalyst is described. The thermal solvent-free and microwave green procedures offer advantages such as shorter reaction times, simple work-up, excellent yield, recovery and reusability of catalyst. It is noteworthy that 1-amidomethyl-2-naphthols can be converted in to important 'drug like' 1-aminomethyl-2-naphthols derivatives by amide hydrolysis reaction.
\end{abstract}

Keywords: Sodium hydrogen sulphate, amidoalkyl naphthol, multi-component reaction, heterogeneous catalyst

\section{Introduction}

Multi-component reactions have attracted a considerable attention in organic syntheses as they can produce the target products in a single operation without isolating the intermediates and thus reducing the reaction times and energy. ${ }^{1,2}$ Heterogeneous catalysts have gained much importance in recent years due to economic and environmental considerations. ${ }^{3}$ Toxic, homogeneous, corrosive liquid acid catalysts, such as $\mathrm{H}_{2} \mathrm{SO}_{4}, \mathrm{HF}, \mathrm{HBr}, \mathrm{HCl}$, and $\mathrm{CF}_{3} \mathrm{COOH}$ are frequently used in organic synthesis. ${ }^{4}$ Organic synthesis involving green processes and under solvent-free conditions have been investigated world widely due to stringent environment and economic regulations. ${ }^{5}$ However, processes involving conventional acids are inherently associated with problems such as high toxicity, corrosive and polluting reagents, catalyst waste, and difficulty in separation and recovery of products. ${ }^{6}$ Thus, replacement of these conventional acids by solid heterogeneous catalysts is desirable to achieve effective catalyst handling, product purification and to decrease waste production. ${ }^{7}$ In this research, $\mathrm{NaHSO}_{4} \cdot \mathrm{H}_{2} \mathrm{O}$ as the solid heterogeneous acid catalyst deserves special mention. This reusable catalyst is safe, inexpensive, easy to handle, and

\footnotetext{
* To whom correspondence should be addressed. Tel: 0098-541-2446565, Fax: 0098-541-2431067.
} 
environmentally benign, presents fewer disposal problems and is stable in reaction media. Sodium hydrogen sulfate $\left(\mathrm{NaHSO}_{4} \cdot \mathrm{H}_{2} \mathrm{O}\right)$ has been demonstrated to be an efficient catalyst for several important reactions such as synthesis of acyl-diazenes, ${ }^{8}$ Friedel-Crafts reactions of carbonyl compounds with heteroaromatic compounds in water ${ }^{9}$ and deprotection of acetals. ${ }^{10}$ In continuation of our investigation of heterogeneous environmentally friendly catalysts, ${ }^{11,12}$ in this paper, we report an efficient method for the preparation of amidomethyl naphthols using sodium hydrogen sulfate (Scheme 1). It is noteworthy that 1-amidomethyl-2-naphthols can convert to important biological active 1-aminomethyl-2-naphthol derivatives ${ }^{13,14}$ by amide hydrolysis reaction.

The preparation of 1-amidoalkyl-2-naphthols can be carried out by condensation of aryl aldehydes, 2-naphthol and acetonitrile or amide in the presence of Lewis or Brønsted acid catalysts such as Montmorillonite $\mathrm{K} 10$ clay, ${ }^{15} \mathrm{Ce}\left(\mathrm{SO}_{4}\right)_{2},{ }^{16}$ iodine, ${ }^{17} \mathrm{~K}_{5} \mathrm{CoW}_{12} \mathrm{O}_{40} .3 \mathrm{H}_{2} \mathrm{O},{ }^{18} p$ $\mathrm{TSA}^{19}$ and sulfamic acid, ${ }^{20}$ cation-exchanged resins ${ }^{21}$ and silica-sulfuric acid. ${ }^{22}$

However, many of these methodologies suffer from the drawback of green chemistry ${ }^{16,17,23}$ and have been associated with several short comings such as long reaction times, expensive reagents, low product yields and difficulty in recovery and reusability of the catalysts. Due to these problems, development of an efficient and versatile method for the preparation of amidoalkyl-2-naphthols is an important aspect and which is an active going on research area and there is a scope for the further improvement towards mild reaction conditions and improved yields. Herein, we describe practical and inexpensive methods for the preparation of 1amidoalkyl-2-naphthol derivatives via multi-component reactions in the presence of sodium hydrogen sulfate as catalyst (Method A, B and C) (Scheme 1).

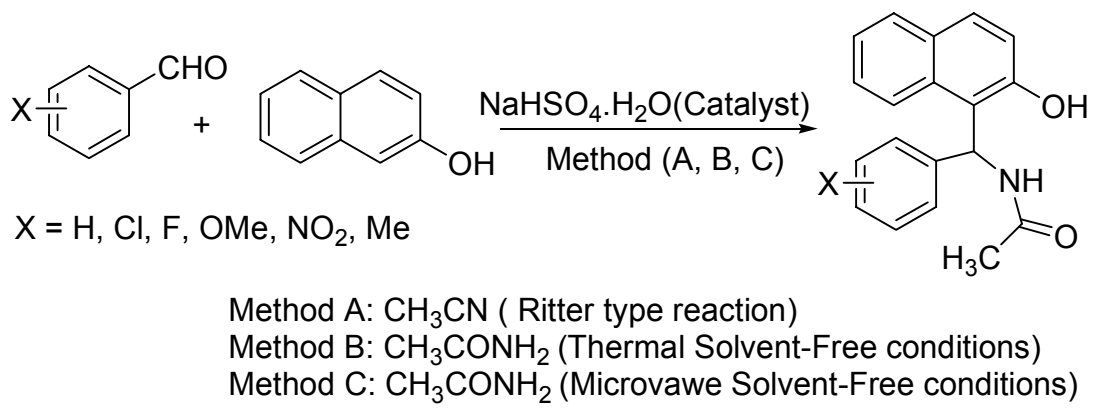

\section{Scheme 1}

\section{Results and Discussion}

The effective amount of sodium hydrogen sulfate as catalyst was investigated. Generally, the reaction rate and yield were increased over the amount of catalyst. It was found that $45 \mathrm{mg}$ of catalyst was the appropriate amount for the reaction. The fewer amounts gave a low yield even after long reaction time, and the more amounts could not cause the obvious increase for the yield 
of product. Hence, the optimal amount of catalyst was chosen $45 \mathrm{mg}$ in the following reactions. Next, we prepared a range of amidoalkyl naphthols under the optimized reaction conditions: 2naphthol, arylaldehydes (1:1), and acetamide $(1.2 \mathrm{mmol})$ or acetonitrile (reactant as well as solvent, $5 \mathrm{~mL})$ in the presence of sodium hydrogen sulfate $(45 \mathrm{mg})$. A series of amidoalkyl naphthols were prepared in high to excellent yields in three methods (A, B and C) (Table 1).

Table 1. Preparation of 1-amidoalkyl-2-naphtols

\begin{tabular}{|c|c|c|c|c|c|}
\hline Entry & Aldehyde & $\begin{array}{l}\text { Method A } \\
\text { Time(h)/ } \\
\text { Yield }(\%)^{\mathrm{a}}\end{array}$ & $\begin{array}{c}\text { Method B } \\
\text { Time (min)/ } \\
\text { Yield (\%) }\end{array}$ & $\begin{array}{c}\text { Method C } \\
\text { Time (min)/ } \\
\text { Yield (\%) }\end{array}$ & $\begin{array}{l}\text { m.p. } \\
{[\text { lit.] }]^{\text {ref. }}}\end{array}$ \\
\hline 1 & & $20 / 80$ & $11 / 86$ & $7 / 82$ & $\begin{array}{c}245-246 \\
{[241-243]^{16}}\end{array}$ \\
\hline 2 & & $20 / 78$ & $35 / 81$ & $10 / 79$ & $222-223$ \\
\hline 3 & & $20 / 88$ & $8 / 93$ & $3 / 89$ & $248-250$ \\
\hline 4 & & $20 / 65$ & $40 / 78$ & $14 / 73$ & $\begin{array}{c}123-125 \\
{[78-79]^{16}}\end{array}$ \\
\hline 5 & & $20 / 79$ & $7 / 87$ & $6 / 82$ & $\begin{array}{c}223-225 \\
{[224-227]^{16}}\end{array}$ \\
\hline 6 & & $20 / 77$ & $7 / 89$ & $6 / 85$ & $\begin{array}{c}227-229 \\
{[228-230]^{15}}\end{array}$ \\
\hline 7 & & $20 / 75$ & $24 / 80$ & $10 / 81$ & $\begin{array}{c}183-185 \\
{[184-186]^{16}}\end{array}$ \\
\hline 8 & & $20 / 84$ & $8 / 94$ & $3 / 91$ & $\begin{array}{c}241-242 \\
{[182-184]^{16}}\end{array}$ \\
\hline 9 & & $20 / 75$ & $8 / 89$ & $7 / 87$ & $248-249$ \\
\hline 10 & & $20 / 72$ & $10 / 86$ & $6 / 85$ & $\begin{array}{c}230-232 \\
{[209-210]^{16}}\end{array}$ \\
\hline
\end{tabular}


11<smiles>O=Cc1ccc(Cl)cc1Cl</smiles>

12<smiles>COc1ccc(OC)c(C=O)c1</smiles>

13<smiles>O=Cc1ccccc1Cl</smiles>

14<smiles>COc1cccc(C=O)c1</smiles>

15<smiles>O=Cc1ccccc1[N+](=O)[O-]</smiles>

16<smiles>Cc1ccccc1C=O</smiles>

17<smiles>COc1ccc(C=O)cc1OC</smiles>

20/79

$8 / 90$

4/91

201-203

${ }^{[198-199]^{16}}$

20/81

20/75

$20 / 84$

$8 / 80$

213-215

[194-196] $]^{22}$

20/71

$17 / 81$

$11 / 78$

201-204

$[203-205]^{15}$

$20 / 80$

$25 / 87$

$12 / 89$

179-182

$[180-182]^{16}$

20/72

30/77

$12 / 74$

199-202

$[200-202]^{22}$

20/77

$5 / 80$

235-237

$[235-236]^{16}$

${ }^{a}$ Yields refer to the pure isolated products. All known products have been reported previously in the literature and were characterized by comparison of IR and NMR spectra with authentic samples [15-22]. Method A: the reaction was carried out with $45 \mathrm{mg}$ of $\mathrm{NaHSO}_{4} \cdot \mathrm{H}_{2} \mathrm{O}$ in acetonitrile (reactant as well as solvent, $5 \mathrm{~mL}$ ) under reflux conditions at $85{ }^{\circ} \mathrm{C}$; reaction time 20h; molar ratio aldehydes/2-naphthol (1/1). Method B: the reaction was carried out under thermal solvent-free conditions in an oil bath at $120{ }^{\circ} \mathrm{C}$; molar ratio aldehydes/2naphthol/acetamide/catalyst $(1 / 1 / 1.2 / 45 \mathrm{mg})$. Method $\mathrm{C}$ : the reaction was carried out in a microwave oven at $800 \mathrm{~W}$ under solvent-free conditions; molar ratio aldehydes/2naphthol/acetamide/catalyst $(1 / 1 / 1.2 / 45 \mathrm{mg}){ }^{\mathrm{b}}$ The references of known products in the literature.

As shown in Table 1, the three-component reaction of 2-naphthol, arylaldehydes, and acetonitrile (reactant as well as solvent, $5 \mathrm{~mL}$ ) or acetamide was performed in the presence of sodium hydrogen sulfate $(45 \mathrm{mg})$. As shown in Table 2, Method A, aromatic aldehydes with substituents carrying either electron-donating or electron-withdrawing groups gave the desired products via a Ritter type reaction ${ }^{24}$ with yields of $65-88 \%$ after $20 \mathrm{~h}$. A mechanistic rationale for 
Method A is shown in Scheme 2. It is suggested that the benzaldehyde first reacts with 2naphthol to give 1-(hydroxyl (aryl) methyl) naphthalene-2-ol I which then reacts with the acetonitrile and produce intermediate II in a Ritter type reaction. Hydrolysis of II gave the desired 1-amidoalkyl-2-naphthol.

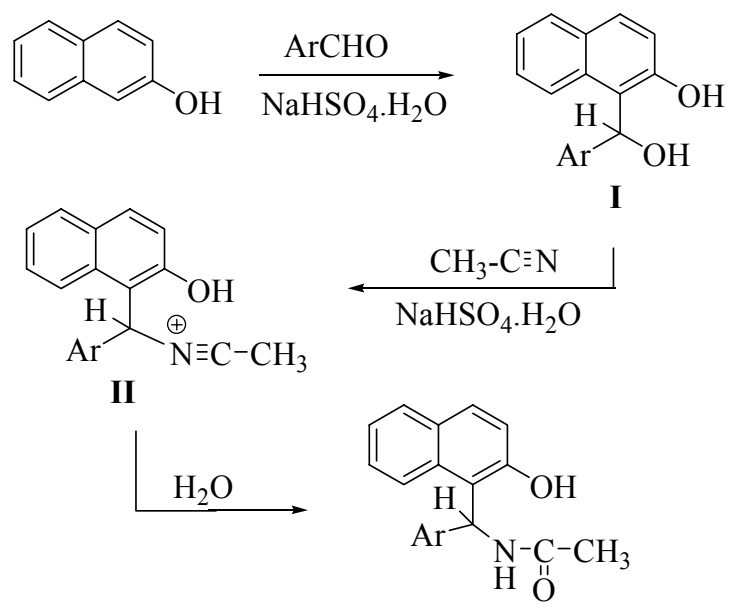

\section{Scheme 2}

In all cases, aromatic aldehydes with substituents carrying either electron-donating or electron-withdrawing groups reacted successfully and gave the products in high yields. It was shown that the aromatic aldehydes with electron withdrawing groups reacted faster than the aromatic aldehydes with electron releasing group as would be expected (Table 1, Method B and C). Aromatic aldehydes with steric hindrance such as 2-nitro and 2-chloro bezaldehydes reacted at long reaction times. The rate reaction of these aldehydes decreased rather than aldehydes with electron donating groups, but the yield of corresponding products is higher than other benzaldehydes derivatives with electron-donating. Aliphatic aldehydes reacted sluggishly and gave side products; hence the desired product could not be isolated. To find the specific effect of microwave irradiation on the reaction, these reactions were carried out under the same conditions in the microwave oven (Table 1, Method C). It was observed that the reaction time decreased considerably. Thus, solvent-free MW conditions found to have beneficial effect on the reaction.

As reported in literature, ${ }^{17-19}$ the reaction of 2-naphthol with aromatic aldehydes in the presence of acid catalyst is known to give ortho-quinone methides ( $O$-QMs). The same $O$-QMs, generated in-situ, have been reacted with acetamide to form 1-amidoalkyl-2-naphthol derivatives. A possible reasonable explanation for this result can be given by considering the nucleophilic addition to $O$-QMs intermediate is favourable via conjugate addition on $\alpha, \beta$ unsaturated carbonyl group that aromatize ring of this intermediate. The electron withdrawing groups substituted on benzaldehyde in $O$-QMs intermediate increase the rate of 1,4-nucleophilic addition reaction because of alkene LUMO is at lower energy in the neighbouring of withdrawing groups than electron donating groups. ${ }^{25}$ 
To show the merit of the present work in comparison with reported results in the literature, we compared results of $\mathrm{NaHSO}_{4} \cdot \mathrm{H}_{2} \mathrm{O}$ with $\mathrm{Ce}\left(\mathrm{SO}_{4}\right)_{2},{ }^{16}$ iodine, ${ }^{17}$ and $\mathrm{K}_{5} \mathrm{CoW}_{12} \mathrm{O}_{40} \cdot 3 \mathrm{H}_{2} \mathrm{O}^{18}$ in the synthesis 1-amidomethyl-2-naphthol derivatives. As shown in Table 2, $\mathrm{NaHSO}_{4} \cdot \mathrm{H}_{2} \mathrm{O}$ can act as effective catalyst with respect to reaction times yields of the obtained products. Thus, the present protocol with $\mathrm{NaHSO}_{4} \cdot \mathrm{H}_{2} \mathrm{O}$ catalyst is convincingly superior to the recently reported catalytic methods.

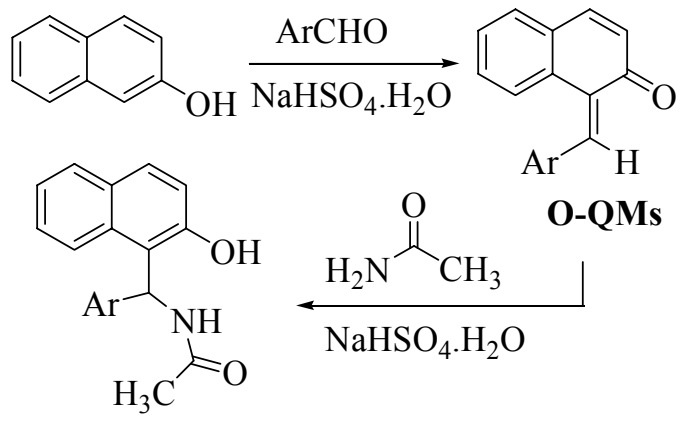

\section{Scheme 3}

Table 2. Comparison result of sodium hydrogen sulfate with $\mathrm{Ce}\left(\mathrm{SO}_{4}\right)_{2},{ }^{16} \mathrm{I}_{2}{ }^{17}$ and $\mathrm{K}_{5} \mathrm{CoW}_{12} \mathrm{O}_{40} \cdot 3 \mathrm{H}_{2} \mathrm{O}^{18}$ in the synthesis of 1-amidoalkyl-2-naphthols

\begin{tabular}{|c|c|c|c|c|c|}
\hline Entry & Aldehyde & Catalyst & $\begin{array}{c}\text { Molar ratio aldehyde / 2- } \\
\text { naphthol/ catalyst; conditions }\end{array}$ & Time & $\begin{array}{c}\text { Yield } \\
(\%)\end{array}$ \\
\hline \multirow{5}{*}{1} & & $\mathrm{Ce}\left(\mathrm{SO}_{4}\right)_{2}$ & 1/1/ (100 mol\%); under reflux & $36 \mathrm{~h}$ & 72 \\
\hline & & $\mathrm{I}_{2}$ & $\begin{array}{l}1 / 1 /(5 \mathrm{~mol} \%) \\
\text { solvent-free } 125^{\circ} \mathrm{C}\end{array}$ & $5.5 \mathrm{~h}$ & 85 \\
\hline & $\mathrm{HO}$ & $\mathrm{K}_{5} \mathrm{CoW}_{12} \mathrm{O}_{40} \cdot 3 \mathrm{H}_{2} \mathrm{O}$ & $\begin{array}{l}1 / 1 /(1 \mathrm{~mol} \%) ; \\
\text { solvent-free, } 125{ }^{\circ} \mathrm{C}\end{array}$ & $2 \mathrm{~h}$ & 90 \\
\hline & & $\mathrm{NaHSO}_{4} \cdot \mathrm{H}_{2} \mathrm{O}$ & 1/1/ $45 \mathrm{mg}$; Method B & $11 \mathrm{~min}$ & 86 \\
\hline & & $\mathrm{NaHSO}_{4} \cdot \mathrm{H}_{2} \mathrm{O}$ & 1/1/45 mg; Method C & $7 \mathrm{~min}$ & 82 \\
\hline \multirow{5}{*}{2} & & $\mathrm{Ce}\left(\mathrm{SO}_{4}\right)_{2}$ & 1/1/ (100 mol\%); under reflux & $36 \mathrm{~h}$ & 56 \\
\hline & & $\mathrm{I}_{2}$ & - & - & - \\
\hline & $\mathrm{Cl}$ & $\mathrm{K}_{5} \mathrm{CoW}_{12} \mathrm{O}_{40} \cdot 3 \mathrm{H}_{2} \mathrm{O}$ & $\begin{array}{l}1 / 1 /(1 \mathrm{~mol} \%) ; \\
\text { solvent-free, } 125^{\circ} \mathrm{C}\end{array}$ & $3 \mathrm{~h}$ & 82 \\
\hline & & $\mathrm{NaHSO}_{4} \cdot \mathrm{H}_{2} \mathrm{O}$ & 1/1/ $45 \mathrm{mg}$; Method B & $8 \mathrm{~min}$ & 90 \\
\hline & & $\mathrm{NaHSO}_{4} \cdot \mathrm{H}_{2} \mathrm{O}$ & 1/1/ $45 \mathrm{mg} ;$ Method C & $4 \mathrm{~min}$ & 91 \\
\hline \multirow{5}{*}{3} & & $\mathrm{Ce}\left(\mathrm{SO}_{4}\right)_{2}$ & 1/1/ (100 mol\%); under reflux & $16 \mathrm{~h}$ & 65 \\
\hline & & $\mathrm{I}_{2}$ & $\begin{array}{l}1 / 1 /(5 \mathrm{~mol} \%) \\
\text { solvent-free, } 125^{\circ} \mathrm{C}\end{array}$ & $5 \mathrm{~h}$ & 81 \\
\hline & $\mathrm{CHO}$ & $\mathrm{K}_{5} \mathrm{CoW}_{12} \mathrm{O}_{40} .3 \mathrm{H}_{2} \mathrm{O}$ & $\begin{array}{l}\text { 1/1/ }(1 \mathrm{~mol} \%) \\
\text { solvent-free, } 125^{\circ} \mathrm{C}\end{array}$ & $3 \mathrm{~h}$ & 78 \\
\hline & & $\mathrm{NaHSO}_{4} \cdot \mathrm{H}_{2} \mathrm{O}$ & 1/1/ $45 \mathrm{mg}$; Method B & $8 \mathrm{~min}$ & 94 \\
\hline & & $\mathrm{NaHSO}_{4} \cdot \mathrm{H}_{2} \mathrm{O}$ & 1/1/ $45 \mathrm{mg} ;$ Method C & $3 \mathrm{~min}$ & 91 \\
\hline
\end{tabular}


The reusability of the catalysts is one of the most important benefits and makes them useful for commercial applications. Thus the recovery and reusability of catalyst was investigated. The recyclability of the catalyst in the reaction of benzaldehyde and 2-naphthol in the presence of $\mathrm{NaHSO}_{4} \cdot \mathrm{H}_{2} \mathrm{O}$ (45 mg) was checked (Table 3, Method A, B and C). The separated catalyst can be reused after washing with $\mathrm{CHCl}_{3}$ and drying at $100{ }^{\circ} \mathrm{C}$. The catalyst was recovered in excellent yields and catalyst was used in the mentioned reaction for five times, it showed the same activity such as fresh catalyst without any loss of its activity.

Table 3. Recyclability of the catalyst in the reaction of benzaldehyde and 2-naphthol in the presence of acetamide using $\mathrm{NaHSO}_{4} \cdot \mathrm{H}_{2} \mathrm{O}^{\text {a }}$ (45 mg)

\begin{tabular}{cccc}
\hline \multirow{2}{*}{ Run No. } & Method A & Method B & Method C \\
\cline { 2 - 4 } & Yield (\%) & Yield (\%) & Yield (\%) \\
\hline 1 & 97 & 96 & 96 \\
2 & 95 & 95 & 96 \\
3 & 98 & 93 & 92 \\
4 & 94 & 94 & 93 \\
5 & 90 & 92 & 91 \\
\hline
\end{tabular}

${ }^{\mathrm{a}}$ Yields refer to the pure isolated recovered catalyst

In conclusion, we have demonstrated that sodium hydrogen sulfate is a new efficient and green catalyst for synthesis of 1-amidoalkyl-2-naphthols. 1-Amidoalkyl-2-naphthol derivatives were prepared via a three-component reaction of an aryl aldehydes, 2-naphthol, and acetonitrile or acetamide in the presence of catalytic sodium hydrogen sulfate in three conditions. The thermal solvent-free and microwave green procedures offer advantages such as shorter reaction times, simple work-up, environmentally benign, excellent yield, cost effective recovery and reusability of catalyst for a number of times without appreciable loss of activity.

\section{Experimental Section}

General Procedures. All reagents were purchased from Merck and Aldrich and used without further purification. All yields refer to isolated products after purification. Products were characterized by comparison with authentic samples and by spectroscopy data (IR, ${ }^{1} \mathrm{H}$ NMR spectra). The NMR spectra were recorded on a Bruker Avance DPX $500 \mathrm{MHz}$ instrument. The spectra were measured in DMSO- $\mathrm{d}_{6}$ relative to TMS $(0.00 \mathrm{ppm})$. Mass spectra were recorded on an Agilent technologies 5973 network mass selective detector (MSD) operating at an ionization potential of $70 \mathrm{eV}$. Elemental analyses for $\mathrm{C}, \mathrm{H}$, and $\mathrm{N}$ were performed using a Heraeus CHN-ORapid analyzer. Melting points were determined in open capillaries with a BUCHI 510 melting point apparatus. TLC was performed on silica-gel polygram SIL G/UV 254 plates. 
General procedure: sodium hydrogen sulfate catalyzed preparation of amidoalkyl naphthols

(a) Under reflux conditions. Method A. To a solution of 2-naphthol (1 mmol) and benzaldehyde $(1 \mathrm{mmol})$ in acetonitrile $(5 \mathrm{~mL}$, reactant as well as solvent), effective amount of $\mathrm{NaHSO}_{4} \cdot \mathrm{H}_{2} \mathrm{O}\left(45 \mathrm{mg}\right.$ ) was added, then the reaction mixture was stirred for $20 \mathrm{~h}$ at $85{ }^{\circ} \mathrm{C}$ under reflux condition. Reaction progress was monitored by TLC. After completion of the reaction, the reaction mixture was filtered and the heterogeneous catalyst was recovered. Then solution was concentrated to solidify. The solid product was purified by recrystallization in aqueous EtOH (15\%).

(b) Solvent free thermal method. Method B. To a mixture of 2-naphthol (1 mmol), aldehydes $(1 \mathrm{mmol})$ and acetamide $(1.2 \mathrm{mmol}), \mathrm{NaHSO}_{4} \cdot \mathrm{H}_{2} \mathrm{O}(45 \mathrm{mg})$ was added. The mixture was stirred at $120{ }^{\circ} \mathrm{C}$ in oil bath and the reaction was followed by TLC. After completion of reaction, mass was cooled to $25^{\circ} \mathrm{C}$, then the solid residue was disolved in EtOAc and the mixture stirred for 5 min. The catalyst was recovered. Then solvent was evaporated, the remained solid product was recrystallized in aqueous EtOH (15\%).

(c) Solvent free microwave irradiation method. Method C. To a mixture of aldehyde (1 mmol) and 2-naphthol (1 mmol), acetamide (1.2 mmol), $\mathrm{NaHSO}_{4} \cdot \mathrm{H}_{2} \mathrm{O}(45 \mathrm{mg})$ was added and the mixture was inserted in a microwave oven (Samsung model KE300R) at $800 \mathrm{~W}$ for the appropriate time. The reaction was followed by TLC. After completion of reaction, mass was cooled to $25^{\circ} \mathrm{C}$, then the solid residue was dissolved in EtOAc and the mixture stirred for 5 min. The catalyst was recovered. Then solvent was evaporated, the remaining solid product was recrystallized in aqueous EtOH (15\%).

The desired pure product(s) was characterized by comparison of their physical data with those of known compounds. ${ }^{15-20}$ The spectral data of the new amidoalkyl naphthols are given below.

$\boldsymbol{N}$-[(4-Methylphenyl)-(2-hydroxynapthalen-1-yl)-methyl]-acetamide (Table 1, entry 2). M.p.: 222-223 ${ }^{\circ} \mathrm{C} ;{ }^{1} \mathrm{H}$ NMR (500 MHz, DMSO-d $)$ ): $\delta=1.96$ (s, 3H), 2.21(s, 3H), 7.08-7.03(m, $5 \mathrm{H}), 7.19(\mathrm{~d}, J=8.8 \mathrm{~Hz}, 1 \mathrm{H}), 7.24(\mathrm{t}, J=7.1 \mathrm{~Hz}, 1 \mathrm{H}), 7.34(\mathrm{~m}, 1 \mathrm{H}), 7.74(\mathrm{~d}, J=8.8 \mathrm{~Hz}, 1 \mathrm{H})$, $7.78(\mathrm{~d}, J=7.9 \mathrm{~Hz}, 1 \mathrm{H}), 7.82(\mathrm{brd}, 1 \mathrm{H}), 8.36(\mathrm{~d}, J=8.1 \mathrm{~Hz}, 1 \mathrm{H}), 9.91(\mathrm{~s}, 1 \mathrm{H}) \mathrm{ppm} . ;{ }^{13} \mathrm{C}$ NMR $(125$ MHz, DMSO-d 6 ): 20.4, 22.6, 47.6, 118.4, 118.9, 122.2, 123.1, 125.9, 126.1, 128.3, 128.4, 128.9, 132.2, 134.9, 139.4, 143.3, 152.9, 168.9 ppm.; IR (KBr, cm $\left.{ }^{-1}\right): 3419,3316,3070,1621,1595$, 1561, 1514, 1466, 1392, 1283, 1202, 1141, 1051, 939, 884, 784, 745, 712.; MS (EI, 70 eV): $\mathrm{m} / z$ $=305\left(\mathrm{M}^{+}, 21.00 \%\right), 246(29.16 \%), 245(50.55 \%), 231(100.00 \%), 232(31.20 \%), 202(16.12 \%)$, 115(10.04\%); Anal. Calcd. for $\mathrm{C}_{20} \mathrm{H}_{19} \mathrm{NO}_{2}$ : C: 78.66; H: 6.27; N: $4.59 \%$. Found: C: 78.72; H: $6.21 ; \mathrm{N}: 4.63 \%$.

$\mathbf{N}$-[(4-Nitrophenyl)-(2-hydroxynapthalen-1-yl)-methyl]-acetamide (Table 1, entry 3). M.p. 248-250 ${ }^{\circ} \mathrm{C} ;{ }^{1} \mathrm{H}$ NMR $\left(500 \mathrm{MHz}, \mathrm{DMSO}_{6}\right): \delta=2.02(\mathrm{~s}, 3 \mathrm{H}), 7.19(\mathrm{~d}, J=8.0,1 \mathrm{H}), 7.22(\mathrm{~d}, J=$ $8.8,1 \mathrm{H}), 7.28(\mathrm{t}, J=7.47 \mathrm{~Hz}, 1 \mathrm{H}), 7.41(\mathrm{t}, J=7.34,1 \mathrm{H}), 7.52-7.58(\mathrm{~m}, 2 \mathrm{H}), 7.81(\mathrm{t}, J=9.38 \mathrm{~Hz}$, $2 \mathrm{H}), 7.89(\mathrm{brd}, 1 \mathrm{H}), 8.05-8.03(\mathrm{~m}, 2 \mathrm{H}), 8.60(\mathrm{~d}, J=8.0 \mathrm{~Hz}, 1 \mathrm{H}), 10.11(\mathrm{~s}, 1 \mathrm{H}) \mathrm{ppm} .{ }^{13} \mathrm{C} \mathrm{NMR}$ (125MHz, DMSO-d 6 ): 22.5, 47.6, 117.7, 118.4, 120.3, 121.1, 122.5, 126.7, 128.6, 129.4, 129.8, 132.1, 132.7, 145.3, 147.7, 153.2, 169.5 ppm.; IR (KBr, $\left.\mathrm{cm}^{-1}\right): 3391,3267,2593,1648,1603$, 
1522, 1438, 1063, 825, 739, 447.; MS (EI, $70 \mathrm{eV}): m / z=336\left(\mathrm{M}^{+}, 26.66 \%\right), 319(75.99 \%)$, 276(52.02\%), 260(54.15\%), 231(63.80\%), 202(45.11\%), 230(100.00\%), 115(18.05\%); Anal. Calcd. for $\mathrm{C}_{19} \mathrm{H}_{16} \mathrm{~N}_{2} \mathrm{O}_{4}$ : C: 67.85; H: 4.79; N: $8.33 \%$. Found: C: 67.91; H: 4.81; N: $8.24 \%$.

$\mathrm{N}$-[(3-Fluorophenyl)-(2-hydroxynapthalen-1-yl)-methyl]-acetamide (Table 1, entry 9). M.p. $248-249^{\circ} \mathrm{C} ;{ }^{1} \mathrm{H}$ NMR $\left(500 \mathrm{MHz}, \mathrm{DMSO}_{6}\right): \delta=1.98(\mathrm{~s}, 3 \mathrm{H}), 6.98-6.92(\mathrm{~m}, 3 \mathrm{H}), 7.12(\mathrm{~d}, J=8.3$ $\mathrm{Hz}, 1 \mathrm{H}), 7.27-7.19(\mathrm{~m}, 3 \mathrm{H}), 7.37(\mathrm{t}, J=7.3 \mathrm{~Hz}, 1 \mathrm{H}), 7.76(\mathrm{~d}, J=8.6 \mathrm{~Hz}, 1 \mathrm{H}), 7.80(\mathrm{~d}, J=8.0 \mathrm{~Hz}$, 1H), 7.84(brd, 1H), 8.44(d, $J=8.2 \mathrm{~Hz}, 1 \mathrm{H}), 10.01(\mathrm{~s}, 1 \mathrm{H}) \mathrm{ppm}$.; ${ }^{13} \mathrm{C}$ NMR $(125 \mathrm{MHz}$, DMSO$\left.\mathrm{d}_{6}\right): 22.5,47.5,112.5\left(\mathrm{~d},{ }^{2} J_{\mathrm{C}-\mathrm{F}}=22.1 \mathrm{~Hz}\right), 112.7\left(\mathrm{~d},{ }^{2} J_{\mathrm{C}-\mathrm{F}}=20.9 \mathrm{~Hz}\right), 118.3,118.4,122.1\left(\mathrm{~d},{ }^{4} J_{\mathrm{C}-\mathrm{F}}=\right.$ $2.5 \mathrm{~Hz}), 122.4,122.9,126.4,128.3,128.5,129.4,129.8\left(\mathrm{~d},{ }^{3} J_{\mathrm{C}-\mathrm{F}}=8.1 \mathrm{~Hz}\right), 132.1,145.9\left(\mathrm{~d},{ }^{3} J_{\mathrm{C}-\mathrm{F}}=\right.$ $6.6 \mathrm{~Hz}), 153.1,162.0\left(\mathrm{~d},{ }^{1} J_{\mathrm{C}-\mathrm{F}}=241.2 \mathrm{~Hz}\right), 169.3$ ppm.; IR $\left(\mathrm{KBr}, \mathrm{cm}^{-1}\right): 3410,3160,1640,1589$, 1545, 1484, 1439, 1335, 1280, 1064, 989, 814, 760, 743. MS (EI, $70 \mathrm{eV}): \mathrm{m} / z=310(\mathrm{M}+1$, $4.79 \%), \quad 309\left(\mathrm{M}^{+}, \quad 21.45 \%\right), \quad 251(9.00 \%), \quad 250(51.75 \%), \quad 249(100.00 \%), \quad 231(14.44 \%)$, 220(16.11\%), 122(7.31\%), 115(9.01\%); Anal. Calcd. for $\mathrm{C}_{19} \mathrm{H}_{16} \mathrm{FNO}_{2}: \mathrm{C}: 73.77 ; \mathrm{H}: 5.21$; $\mathrm{N}$ : $4.53 \%$. Found: C: 73.74 ; H: 5.25 ; N: $4.48 \%$.

$\mathrm{N}$-[(2,5-Dimethoxyphenyl)-(2-hydroxynapthalen-1-yl)-methyl]-acetamide (Table 1 , entry 12). M.p. $251-253{ }^{\circ} \mathrm{C} ;{ }^{1} \mathrm{H}$ NMR (500 MHz, DMSO-d $\left.)\right): \delta=1.88$ (s, 3H), 3.48(s, 3H), 3.64(s, $3 \mathrm{H}), 6.77-6.72(\mathrm{~m}, 2 \mathrm{H}), 7.23-7.10(\mathrm{~m}, 4 \mathrm{H}), 7.39(\mathrm{~s}, 1 \mathrm{H}), 7.73-7.66(\mathrm{~m}, 2 \mathrm{H}), 8.27-8.15(\mathrm{~m}, 2 \mathrm{H})$, 9.75(s, 1H) ppm.; ${ }^{13} \mathrm{C}$ NMR (125 MHz, DMSO-d 6 ): 22.5, 44.4, 55.2, 55.9, 111.1, 111.9, 115.7, $118.5,118.9,122.0,123.2,125.7,128.1,128.6,131.7,132.4,150.7,152.7,153.1,168.1$ ppm.; IR (KBr, cm $\left.{ }^{-1}\right): 3365,3174,3002,2939,1614,1577,1497,1436,1370,1317,1277,1218,1084$, 1052, 819, 797, 727.; MS (EI, $70 \mathrm{eV}): m / z=351\left(\mathrm{M}^{+}, 17.83 \%\right), 308(5.82 \%), 276$ (5.87\%), 262 (36.04\%), $261(100.00 \%), 218(16.71 \%), 144(6.60 \%), 115$ (7.99\%); Anal. Calcd for $\mathrm{C}_{21} \mathrm{H}_{21} \mathrm{NO}_{4}$ : C: 71.78; H: 6.02; N: $3.99 \%$. Found: C: 71.73; H: 5.93; N: $4.08 \%$.

\section{Acknowledgements}

We are thankful to the Sistan and Baluchestan University Research Council for the partial support of this research.

\section{References}

1. Zhu, J.; Bienaymé, H.; Multicomponent Reactions, Wiley-VCH: Weinheim, Germany, 2005.

2. Dömling, A.; Ugi, I. Angew. Chem. Int. Ed. 2000, 39, 3168.

3. Santen, V. R. A.; Neurock, M. Molecular Heterogeneous Catalysis: A Conceptual and Computational Approach, Wiley-VCH: Weinheim, Cambridge, 2006.

4. Van Leeuwen, P. W. Homogeneous Catalysis: Understanding the Art, Kluwer Academic Publishers, 2004.

5. Corma, A.; Garcia, A. Chem. Rev. 2003, 103, 4307. 
6. Clark, J. H.; Rhodes, C. N. Clean Synthesis Using Porous Inorganic Solid Catalysts and Supported Reagents, Royal Society of Chemistry, 2000.

7. Gerard, V. S.; Notheisz, F. Heterogeneous Catalysis in Organic Chemistry, Elsevier, 2000.

8. $\quad$ Li, J. P.; Liu, P.; Wang, Y. L. Chin. Chem. Lett. 2003, 14, 677.

9. Mirjalili, B. F.; Zolfigol, M. A.; Bamoniri, A.; Hazar, A. Bull. Korean Chem. Soc. 2004, 25, 1075.

10. Zhuang, W.; Jorgensen, K. A. Chem. Commun. 2002, 1336.

11. Shaterian, H. R.; Shahrekipoor, F.; Ghashang, M. J. Mol. Catal. A: Chem. 2007, 272, 142.

12. Shaterian, H. R.; Ghashang, M.; Hassankhani, A. Dyes Pigm. 2008, 76, 564.

13. Shen, A. Y.; Tsai, C. T.; Chen, C. L. Eur. J. Med. Chem. 1999, 34, 877.

14. Shen, A. Y.; Chen, C. L.; Lin, C. I. Chin. J. Physiol. 1992, 35, 45.

15. Kantevari, S.; Vuppalapati, S. V. N.; Nagarapu, L. Catal. Commun. 2007, 8, 1857.

16. Selvam, N. P.; Perumal, P. T.; Tetrahedron Lett. 2006, 47, 7481.

17. Das, B.; Laxminarayana, K.; Ravikanth, B.; Rao, B. R. J. Mol. Catal. A: Chem. 2007, 261, 180.

18. Nagarapu, L.; Baseeruddin, M.; Apuri, S.; Kantevari, S. Catal. Commun. 2007, 8, 1729.

19. Khodaei, M. M.; Khosropour, A. R.; Moghanian, H. Synlett 2006, 916.

20. Patil, S. B.; Singh, P. R.; Surpur, M. P.; Samant, S. D. Ultrason. Sonochem. 2007, 14, 515.

21. Patil, S. B.; Singh, P. R.; Surpur, M. P.; Samant, S. D. Synth. Commun. 2007, 37, 1659.

22. Srihari, G.; Nagaraju, M.; Murthy, M. M. Helv. Chim. Acta 2007, 90, 1497.

23. Anastas, P. T. Green Chemistry Theory and Practice, Oxford University Press: New York, 2000 .

24. Ritter, J. J.; Minieri, P. P. J. Am. Chem. Soc. 1948, 70, 4045.

25. Anslyn, E. V.; Dougherty, D. A. Modern Physical Organic Chemistry, University Science Books: Sausalito, California, 2006. 